\title{
Costilla cervical en el diagnóstico diferencial de una masa supraclavicular
}

\author{
T. Ballesteros Lara, M. A. Martínez Montes, A. Delgado Sala \\ Pediatras. CS Belén. Jaén. España.
}

Tatiana Ballesteros Lara: ta_b_I@yahoo.es

\begin{abstract}
ป La costilla cervical consiste en una costilla supernumeraria que surge de la séptima vértebra cervical y termina libremente en el tejido del cuello o se articula con la primera costilla. Puede ser asintomática y diagnosticarse como hallazgo casual en una radiografía de tórax, o bien presentarse con dolor en la región supraclavicular o como complicación en forma de síndrome del desfiladero torácico. A menudo plantea diagnóstico diferencial con masas tumorales malignas, por sus características en la exploración. El manejo suele ser conservador y la intervención quirúrgica se reserva para casos muy sintomáticos o

Palabras clave: complicados. Presentamos un caso clínico de costilla cervical sintomática y su abordaje desde Atención

- Costilla cervical

- Masa supraclavicular Primaria.
\end{abstract}

\section{Cervical rib in the differential diagnosis of supraclavicular mass}

Key words:

- Cervical rib

- Supraclavicular mass
Cervical rib is a supernumerary rib arising from the seventh cervical vertebra and ends freely in the tissue of the neck or articulates with the first rib. It can be diagnosed as an asymptomatic incidental finding on a chest radiograph or presented with supraclavicular pain or complications as thoracic outlet syndrome. The differential diagnosis often poses malignant tumor masses, because of their characteristics in the physical exam. The management is often conservative reserving surgical intervention for highly symptomatic or complicated cases. We report a case of symptomatic cervical rib and its approach from Primary Care.

\section{INTRODUCCIÓN}

En la costilla cervical, la apófisis transversa de la séptima vértebra cervical se prolonga más allá de la primera dorsal y su extremo termina libremente o conecta con la primera costilla mediante bandas fibrosas o por fusión completa. Es la anomalía costal más frecuente y se presenta más comúnmente en mujeres, tanto de forma aislada como asociada a otras alteraciones óseas. De su longitud y características dependerán los síntomas que se presenten y, por tanto, su manejo en la consulta de Pediatría.

\section{CASO CLÍNICO}

Niña de diez años que acude a la consulta de Pediatría de Atención Primaria por dolor cervical con- 
tinuo de dos semanas de evolución que aparece de manera espontánea y también a la palpación en la región cervical derecha. Se encuentra afebril, sin otra sintomatología acompañante y sus antecedentes personales carecen de interés. No se refieren antecedentes de traumatismos ni procesos infecciosos las semanas anteriores. En la exploración física solo llama la atención una masa situada en la región laterocervical derecha, que se detecta con la palpación profunda, localizada en el tercio inferior del borde posterior del músculo esternocleidomastoideo (ECM), próxima a la región supraclavicular, indurada, no móvil y mal delimitada, dolorosa a la palpación, sin signos inflamatorios ni relieves en la piel circundante. La niña no refería anorexia ni pérdida de peso.

Ante el cuadro clínico que presentamos, se planteó la posibilidad de una patología tumoral, especialmente maligna por las características de la masa; sin embargo, no descartamos la existencia de otras causas como una contractura o fibrosis del músculo ECM, una infección de la zona, o bien alguna causa congénita como quistes o fístulas. Decidimos iniciar tratamiento antiinflamatorio y revisión en una semana. Pasado este tiempo, el dolor había mejorado parcialmente pero persistía la masa cervical con similares características, por lo que se solicitó un estudio con hemograma, bioquímica y proteína $C$ reactiva $(P C R)$, serologías, prueba de Mantoux, ecografía cervical y radiografía de tórax, y se inició tratamiento antibiótico con amoxicilinaclavulánico en dosis de 100 mg/kg/día.

Pruebas complementarias: hemoglobina, 14,5 g/dl; hematocrito, $41,2 \%$; leucocitos, $8040 / \mu \mathrm{l}$ (43\% neutrófilos, 49\% linfocitos); plaquetas, 356 000; bioquímica: ionograma, glucemia, función renal y hepática normales; lactatodeshidrogenasa, 430 $\mathrm{U} / \mathrm{l}$; tirotropina, 0,97 $\mu \mathrm{UI} / \mathrm{ml}$; PCR, 0,5 mg/l. Prueba de Mantoux negativa. Serologías para toxoplasma, citomegalovirus y virus de Epstein-Barr negativas. Las pruebas de imagen fueron concluyentes, al visualizarse tanto en la radiografía de tórax (Fig. 1) como ecográficamente una malformación costal consistente en una sincondrosis entre dos segmentos costales que partía de la apófisis transver-

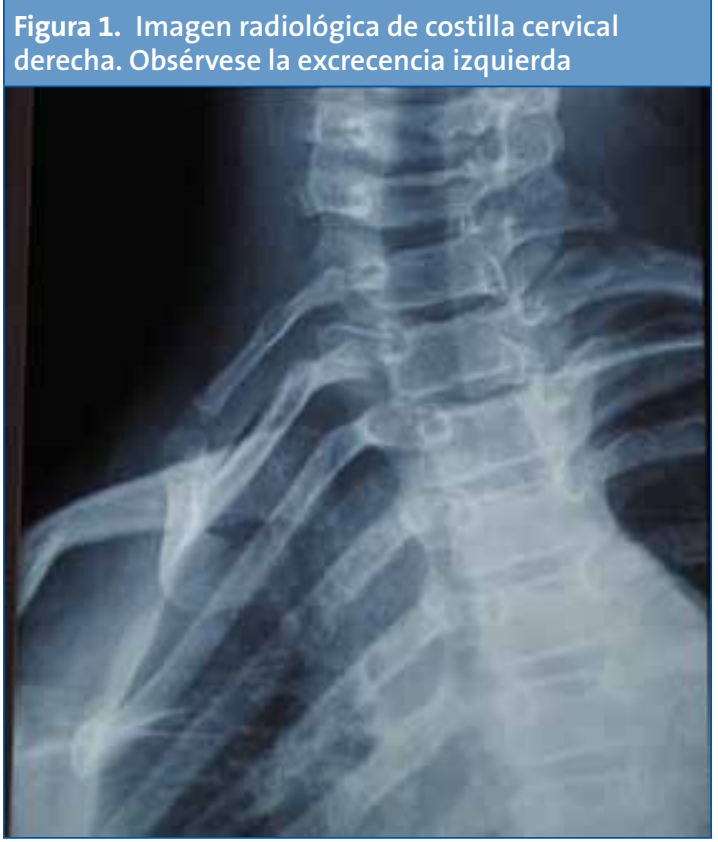

sa de la séptima vértebra crevical derecha, así como un rudimento costal izquierdo que partía de la séptima vértebra cervical izquierda. En conclusión, la niña presentaba una costilla cervical derecha y rudimentaria izquierda. En la actualidad realiza seguimiento en consulta de Pediatría de Atención Primaria y no presenta complicaciones.

\section{DISCUSIÓN}

La costilla cervical es la malformación costal más frecuente (incidencia del 0,2-1\%), y aparece con más frecuencia en mujeres que en varones $(2,5: 1)^{1-4}$. Consiste en una prolongación de la apófisis transversa de la séptima vértebra cervical más allá de la apófisis transversa de la primera vértebra dorsal, puede ser uni- o bilateral $(50-80 \%)^{5}$ y presentarse como un rudimento o una costilla completa. Puede aparecer como anomalía única o asociarse a otras malformaciones óseas, principalmente de columna, o a espina bífida oculta.

En la mayor parte de los casos es asintomática y se diagnostica casualmente al realizar una radiografía de tórax por otro motivo. El 10\% produce síntomas $^{1}$, los más frecuentes de los cuales son dolor 
cervical y presencia de masa cervical sin signos inflamatorios. Su presentación como complicación en forma de síndrome del desfiladero torácico (SDT) es poco frecuente 2 . La costilla cervical o de Eva fue descritra por primera vez en 1869 por Gruber, quien realizó una clasificación en cuatro grupos: 1) costilla cervical que se extiende más allá de la apófisis transversa; 2) cuando además su extremo libre casi toca la primera costilla; 3) cuando aparecen bandas fibrosas o cartilaginosas uniendo la costilla cervical con la primera dorsal, y 4) cuando la fusión con la primera costilla dorsal es completa. Las dos últimas categorías son las que producen complicaciones vasculares con más frecuencia en forma de compresión arterial, trombosis y aneurismas ${ }^{3,5}$.

La presencia de una masa laterocervical en un niño plantea un diagnóstico diferencial en el que se diferencian causas congénitas, como quistes y fístulas branquiales, hematomas y fribrosis del músculo ECM; causas adquiridas, en especial patología tumoral tanto benigna (quistes dermoides, epidermoides, linfangioma quístico, hemangioma, lipoma, pilomatrixoma, teratoma) como maligna (linfoma, rabdomiosarcoma y neuroblastoma), y causas infecciosas, como adenopatías de origen vírico, generalmente precedidas de infección respiratoria o bacterianas que, en el caso de anaerobios, se pueden presentar en pacientes con procesos periodontológicos.

Menos del $2 \%$ de las masas que afectan a cabeza y cuello son tumorales, mientras que cuando la masa se localiza en la región supraclavicular la probabilidad asciende al $50 \%{ }^{4}$, y podría tratarse de linfomas, adenopatías de tumores del mediastino, lesiones pulmonares, rabdomiosarcomas y carcinomas, entre otros. El linfoma es el más frecuente, e un $60 \%$ de los casos es no-Hodgkin, y en el $40 \%$ restante, Hodgkin, muy raro este último en menores de diez años ${ }^{4}$.

Entre los signos de alarma de una masa se incluyen la localización supraclavicular o escalénica, síntomas como pérdida de peso y fiebre presistente, tamaño $>3 \mathrm{~cm}$, inicio neonatal y falta de movilidad en la exploración. En el caso clínico que pre- sentamos no existía antecedente de infección respiratoria. Además, la localización, muy próxima al área supraclavicular, junto con su induración y escasa movilidad, nos hizo pensar en una causa tumoral maligna como probable diagnóstico, sin descartar inicialmente otras etiologías.

En cuanto a la indicación de pruebas diagnósticas, debemos evaluar al comienzo el riesgo de padecer una enfermedad grave, para lo cual están indicados los estudios complementarios (analíticas, serologías, prueba de Mantoux, radiografía de tórax y ecografía) cuando este riesgo es apreciable ${ }^{1,6}$. En nuestro caso, se realizó inicialmente un seguimiento con tratamiento antiinflamatorio, al contemplarse en el diagnóstico diferencial la posibilidad de un origen muscular del cuadro en forma de contractura o fibrosis del ECM, con revisión temprana y posterior indicación de pruebas complementarias por persistir la clínica.

La principal complicación que puede aparecer en la costilla cervical es el SDT, si bien es raro en Pediatría. Suele aparecer en la adolescencia, al crecer las estructuras que componen el desfiladero, aunque resulta más frecuente en la segunda o tercera década de la vida. Es más frecuente en mujeres $(1,5: 1)^{1}$ y consiste en una compresión de las raíces del plexo braquial y la arteria subclavia por la costilla cervical o la banda fibrosa que se forma entre dicha costilla y la primera dorsal. Los síntomas más frecuentes son neurológicos, en forma de parestesias del miembro superior sobre todo a la flexoextensión del cuello, dolor o cansancio de la extremidad. La compresión de la arteria subclavia se objetiva en la exploración, cuando desaparece el pulso radial al abducir el hombro.

Una rara complicación de la costilla cervical es el infarto cerebral. En la revisión bibliográfica realizada encontramos el caso de una niña de 14 años en la que esta complicación fue el síntoma inicial ${ }^{5}$. La compresión crónica de la arteria subclavia por la costilla cervical origina una estenosis en dicha localización con una dilatación posestenosis donde se originan los trombos. Al abducir el hombro, se crea un flujo retrógrado que puede desplazar el trombo hacia la arteria carótida y vertebral, y origi- 
nar el fenómeno tromboembólico y consecuente infarto cerebral. El embolismo de la arteria carótida derecha es más frecuente que el de la arteria vertebrobasilar, y se describe con más frecuencia en pacientes con la costilla cervical situada a la derecha, mientras que la arteria vertebrovasilar se afecta en las costillas cervicales izquierdas.

El tratamiento de la costilla cervical asintomática y del SDT es conservador, evitando aquellos movimientos que incrementen las molestias y realizando ejercicios que fortalezcan la musculatura del hombro. Cuando fracasa este tratamiento, está indicada la resección de la costilla cervical y bandas fibrosas acompañantes. Algunos autores proponen el tratamiento quirúrgico de entrada en los grupos 2 y 3 de Gruber muy sintomáticos y en el grupo 4 de Gruber, debido a la alta probabilidad de complicaciones tromboembólicas, procediendo a la resección no solo de la costilla cervical, sino también de la primera dorsal con excelentes resultados a largo plazo ${ }^{3}$.

\section{BIBLIOGRAFÍA}

1. Falero Gallego MP, Galán Arévalo S, Crespo Rupérez E, Losa Frías V, Ortiz Valentín I. Masa supraclavicular. An Pediatr (Barc). 2007;67:283-4.

2. Chan K, Gitomer S, Perkins J, Liang C, Strain J. Clinical Presentation of Cervical Ribs in the Pediatric Population. J Pediatr. 2013;162:635-6.

3. Zou Chang K, Likes K, Davis K, Demos J, Freischlag JA. The significance of cervical ribs in thoracic outlet syndrome. J Vasc Surg. 2013; 57:771-5.
Consideramos necesario incluir esta anomalía costal en el diagnóstico diferencial de masa cervical no inflamatoria e indurada o dolor cervical en el niño. Tanto es así, que en ocasiones puede resultar suficiente la realización de una radiografía de tórax para llegar al diagnóstico, sin necesidad de realizar otras pruebas complementarias. Debe realizarse un seguimiento a largo plazo, por la posibilidad de complicaciones al crecer las estructuras que componen el desfiladero torácico que, en el caso de costillas cervicales asintomáticas o dolorosas y SDT con síntomas leves, puede realizarse por el equipo de Atención Primaria.

\section{CONFLICTO DE INTERESES}

Los autores declaran no presentar conflictos de intereses en relación con la preparación y publicación de este artículo.

\section{ABREVIATURAS}

ECM: esternocleiomastoideo - PCR: proteína C reactiva - SDT: síndrome del desfiladero torácico.

4. Elias Pollina J, Delgado Alvira R, Burgués Prades P. Masas cervicales. XXII Congreso de la SEPEAP.

5. Kataria R, Sharma A, Srivastava T, Bagaria $\mathrm{H}$, Sharma A. Cervical rib, a rare cause or recurrent stroke in the young. Case report. The Neurologist. 2012;18: 321-3.

6. Martín Jiménez L, Del Rosal Rabes T, Navarro Falcanes C. Adenopatías. En: Guerrero Fernandez J, Ruiz Domínguez JA, Menéndez Suso JJ, Barrios Toscón A (ed.). Manual de Diagnóstico y terapéutica en Pediatría. Madrid: Publimed; 2009. p. 101-5. 